\title{
Cerebral Microvascular and Macrovascular Disease Risk Factors and COVID-19 Progression
}

\author{
Nevio Cimolai \\ Children's and Women's Health Centre of British Columbia, Faculty of Medicine, The University of \\ British Columbia, Vancouver, BC, Canada
}

Dear Editor,

Nia et al. [1] proposed that past cerebrovascular disease history is an independent risk factor for enhanced COVID-19-related morbidity and mortality. The specific categorization of clinical entities that comprise cerebrovascular diseases in their research predominantly emphasizes preexisting macrovascular disease. In its greater breadth, cerebrovascular disease spans a more plenary spectrum of microvascular and/or macrovascular pathology $[2,3]$. Is there any reason to believe that microvascular cerebral diseases are also risk factors for severity?

Chronic hypertension and its associated microvascular disease is lesser understood as among the spectrum of cerebrovascular diseases $[4,5]$. Such pathology is initiated early in the course of chronic hypertension and may have a variable progressive pattern thereafter [6]. Given the latter, it would be tempting to hypothesize that such disease and its associated endotheliopathy may provide the right preconditions to complicate the thrombotic tendencies of active SARS-CoV-2 infection [7]. Both univariate and multivariate analyses have associated the precondition of hypertension with increased risk for more severe COVID-19 [8-10]. Systematic reviews also provide further corroboration for the latter $[11,12]$. Also in pregnancy, hypertension associates with severity of infection [13].
In this light, it would be of interest to determine if the data from Nia et al. [1] gives rise to similar findings for the association of hypertension and worse outcome. Moreover, it would be of value to determine if hypertension and the clinical macrovascular cerebrovascular diseases independently associate with worse COVID-19 or simply associate as co-variates. Such analyses have the potential to broaden our understanding of COVID-19-related endothelial disease for active infection, thrombosis, and potentially vaccine-related complications.

\section{Conflict of Interest Statement}

The author has no conflicts of interest to declare.

\section{Funding Sources}

There are no funding sources to declare.

\section{Author Contributions}

Nevio Cimolai is the sole author. karger@karger.com www.karger.com/ced (c) 2021 S. Karger AG, Basel

Karger!
Correspondence to:

Nevio Cimolai, ncimolai@mail.ubc.ca 


\section{References}

1 Nia AM, Srinivasan VM, Hayworth MK, Lall RR, Kan P. A history of cerebrovascular disease is independently associated with increased morbidity and mortality in patients with COVID-19: a cohort study of 369,563 COVID-19 cases in the USA. Cerebrovasc Dis. 2021 Aug 6:1.

2 Harsha KJ. Imprecise eponyms in stroke medicine: a growing need for uniform terminologies/definitions across the globe. Neurol India. 2019 Mar-Apr;67(2):364-9.

3 Cimolai N. Reader response: white matter hyperintensities mediate the association of nocturnal blood pressure with cognition. Neurology. 2021 July 6;97(1):45.

4 World Health Organization. Cerebrovascular disorders: a clinical and research classification. WHO Offset Publication No. 43, World Health Organization; 1978.

5 Cimolai N. Cerebrovascular disease integration of chronic kidney disease and hyperten- sion. J Stroke Cerebrovasc Dis. 2021;30: 105519.

6 Agabiti-Rosei E, Rizzoni D, Cunha P. Chapter 5. Pathophysiology of Brain Damage in hypertension: small vessel disease. In: Coca A, editor. Hypertension and brain damage. Switzerland: Springer; 2016.

7 Cimolai N. Untangling the intricacies of infection, thrombosis, vaccination, and antiphospholipid antibodies for COVID-19. SN Compr Clin Med. 2021 June 22:1-16.

8 Garcia-Lamberechts EJ, Ò Miró, Fragiel M, Llorens $\mathrm{P}$, Jiménez S, Piñera $\mathrm{P}$, et al. A casecontrol analysis of stroke in COVID-19 patients: results of unusual manifestations of COVID-19 study. Acad Emer Med. 2021 Sep 7.

9 Tornhammar P, Jernberg T, Bergström G, Blomberg A, Engström G, Engvall J, et al. Association of cardiometabolic risk factors with hospitalization or death due to COVID-19: population-based cohort study in Sweden
(SCAPIS). BMJ Open. 2021 Sep 2;11(9): e051359.

10 Vahey GM, McDonald E, Marshall K, Martin SW, Chun H, Hewlihy R, et al. Risk factors for hospitalization among persons with COVID-19: Colorado. PLoS One. 2021 Sep 2; 16(9):e0256917.

11 Dessie ZG, Zewotir T. Mortality-related risk factors of COVID-19: a systematic review and meta-analysis of 42 studies and 423,117 patients. BMC Infect Dis. 2021 Aug 21;21(1):855.

12 Hoang T, Anh TTT. Comparison of comorbidities in relation to critical conditions among Coronavirus Disease 2019 patients: a network meta-analysis. Infect Chemother. 2021 Mar 5;53(1):13-28.

13 Vouga M, Favre G, Martinez-Perez O, Pomar L, Forcen Arcebal L, Abascal-Saiz A, et al. Maternal outcomes and risk factors for COVID-19 severity among pregnant women. Sci Rep. 2021 Jul 6;11(1):13898. 